Letrônica, Porto Alegre, v. 7, n. 2, p. 1075-1089, jul./dez., 2014

\title{
A VIAGEM EXISTENCIAL EM ANTONIO DE BEATRIZ BRACHER
}

\author{
THE EXISTENTIAL JOURNEY IN THE WORK OF BEATRIZ BRACHER
}

Silvia Barros*

\begin{abstract}
Resumo: 0 presente artigo faz uma exposição do tema da viagem que se desdobra espacial e existencialmente. 0 personagem Teo, narrado pelas vozes de três diferentes narradores, é o viajante que, em sua jornada, sofre transmutação física e psicológica, seguindo um destino trágico que o leva à loucura. A tripla narração se revela como forma narrativa original no romance Antonio e permite uma leitura que se descola do simples conhecimento dos acontecimentos e nos leva à interpretação dos sentidos da própria viagem.

Palavras-chave: Literatura Contemporânea; Viagem; Trágico.
\end{abstract}

\begin{abstract}
This article is a presentation of the theme of the journey that unfolds spatially and existentially. The character Teo, narrated by the voices of three different narrators, is the traveler on his journey, suffering physical and psychological transmutation, following a tragic fate that leads to madness. The triple narration reveals itself as original narrative in the novel Antonio and allows a reading that moves away from the simple knowledge of the events and leads us to the interpretation of the meanings of their own journey.
\end{abstract}

Keywords: Contemporary Literature; Journey; Tragic.

\section{Introdução}

0 título do romance é Antonio. Os narradores são Raul, Isabel e Haroldo. 0 ouvinte da narração é Benjamim. O protagonista é Teo.

Por todas essas bocas, por esse ouvido e pelo nome daquele que ainda não nasceu, mas dá título ao livro, conhecemos o andarilho existencial Teo. Conhecemos, na verdade, vários em um só, que se transmutam através do tempo e das diversas experiências que cada um dos narradores desvela a seu filho, Benjamim, ao longo do romance. Conhecemos também os narradores, pois, através de sua narração, vão revelando quem são no processo de produzir da massa da linguagem uma figura que se

\footnotetext{
${ }^{*}$ Mestre em Literatura Brasileira pela UFRJ, doutoranda em Literatura Brasileira pela UFRJ, professora do ensino básico, supervisora do Programa de Iniciação à Docência (CAPES/UFF).
} 
forma, deforma e reforma. Teo é a morte e a vida de seus ancestrais e de seus descendentes, construindo uma árvore genealógica de galhos que se bifurcam e se recompõem mais adiante.

Beatriz Bracher coloca em Teo o signo da loucura, porque é impossível seguir em frente quando o destino trágico está diante de seus olhos desde o primeiro momento. Tal signo se impõe tanto no corpo do personagem como nas cenas que ele protagoniza. 0 embate entre o belo e o grotesco representa a desarmonia trágica existencial.

\begin{abstract}
A harmonia serena, entendida como ordem e medida, exprime-se naquela que Nietzsche chama de Beleza Apolínea. Mas esta beleza é ao mesmo tempo um anteparo que tenta cancelar a presença de uma beleza Dionisíaca, conturbadora, que não se exprime nas formas aparentes, mas além das aparências. É uma Beleza alegre e perigosa, antitética à razão e frequentemente representada como possessão e loucura: é o lado noturno do suave céu ático, povoado de mistérios iniciáticos e obscuros ritos sacrificiais, como os mistérios eleusinos e os ritos dionisíacos. Essa Beleza noturna e conturbadora permanecerá escondida até a idade moderna, para configurar-se depois como reservatório secreto e vital das expressões contemporâneas da Beleza, realizando a sua desforra contra a bela harmonia clássica. (ECO, 2004, p. 58).
\end{abstract}

A beleza dionisíaca proposta por Nietzsche e interpretada na arte por Umberto Eco se traduz na obra de Bracher por meio das transformações do corpo de Teo ao longo de suas viagens, que são, além de geográficas, existenciais. Como sugere o teórico, essa possibilidade estética, que remete à antiguidade, ganha terreno fértil na contemporaneidade, quando as incertezas íntimas disputam espaço com as ideologias globalizadas. Dessa forma, impõe-se a presença do trágico, já visto por críticos da literatura contemporânea, como Beatriz Resende (2008), como elemento comum nas narrativas de nosso tempo.

0 romance de Beatriz Bracher, aqui analisado, tem a característica de representar um protagonista morto, mas vivo pela memória de seus parentes. Os narradores não relatam os acontecimentos da vida de Teo, eles os interpretam, buscam dar sentido à vida de Teo, fazendo, ao mesmo tempo, uma análise íntima de suas próprias vidas.

0 romance triplamente narrado recompõe para Benjamim a história de seu pai, viajante existencial, desde sua juventude até sua morte. Teo é caracterizado, desde o início do romance, como diferente, especial, alguém com habilidades encantadoras. Entretanto, ele recusa todos os rótulos: 
A dificuldade era escolher o que fazer. Ele era o cara mais talentoso do nosso grupo, escrevia, desenhava, compunha, tocava, tudo e qualquer coisa e sempre bem. Desde o primário ele era impressionante em matemática, vários níveis acima de todos os colegas, tudo era fácil para ele. Talvez por isso mesmo ele hesitasse e a verdade é que no último ano vinha se esforçando para ser mau aluno. Depois dessa conversa com o pai, parece que juntou umas coisas na cabeça, coisas já de antes com outras que fantasiou e resolveu que não ia fazer faculdade. Estava de saco cheio de São Paulo e queria dar um tempo, viajar, conhecer o sertão, coisas que hoje não fazem muito sentido, mas que estavam dentro das nossas possibilidades. (BRACHER, 2007, p. 13).

Teo decide não seguir nenhum de seus talentos, não deseja ser artista, nem cursar faculdade. Após conhecer a história pregressa de seu pai - que quase enlouqueceu após perder o filho que tivera com a primeira mulher - Teo tem a certeza de que os caminhos óbvios são uma suposta liberdade, imposta pelos valores construídos pelos outros.

Assim, a rejeição de Teo aos moldes convencionais de vida é o primeiro indício de que é necessário ter liberdade para buscar a existência interior. Pode-se dizer que o Antonio é um romance de formação às avessas. Teo não se torna o homem autoconsciente, plenamente formado, crítico e civilizado. Ele se despe, ao longo da narrativa, de todos esses estereótipos. Tal recurso é possível na literatura contemporânea, em que se vê uma crise da representação da realidade social. Não se trata apenas de questões de gênero, classe, sexualidade ou política. Trata-se da questão existencial do ser humano de hoje e de sempre.

Teo encena um drama dionisíaco, pois, assim como o deus Dioniso, que nasce e morre constantemente, ele decide viajar e viver outros lugares para se destruir e se reconstruir.

\section{Beatriz Bracher e a narração multivocal}

Ao tomarmos em nossas mãos o romance de Beariz Bracher, publicado em 2007, nos deparamos com um nome: Antonio. Quando abrimos a página que inicia a narrativa vemos o título do capítulo: Raul. A primeira palavra que lemos é Teo. Descobrimos que não se trata de um romance baseado em acontecimentos, até mesmo porque o protagonista do romance, Teo, já está morto. Descobrimos que se trata de uma narrativa de pessoas, da tentativa de exteriorizar, poeticamente, por meio da linguagem, os interiores. 
Beatriz Bracher faz uma escolha que nos remete a Graciliano Ramos, em Vidas Secas, ao narrar cada capítulo sob um ponto de vista diferente. Entretanto, no caso da autora, cada ponto de vista é apresentado pelo próprio narrador-personagem que vai contar a Benjamim, ouvinte das histórias, suas experiências de vida relacionadas a Teo. O resultado é uma colcha de retalhos em que a cronologia - e a lógica, de modo geral - é abandonada para dar espaço ao tempo da emoção de reviver, ao narrar, momentos que reescrevem a história de Teo.

Transformação e conservação são palavras em jogo nas três narrativas em uma. Transformação, pois ao contar não fazem apenas um relato biográfico do personagem, mas sim uma revisitação aos sentimentos vividos na época em face a uma nova percepção do que viveram e do impacto que aquilo teve em suas vidas. Conservação, pois o objetivo de Benjamim é produzir conhecimento sobre seu pai para transmitir ao filho, Antonio, fazendo, assim, com que não se percam os fios dos laços de família. Laços esses que são mais apertados nos pontos em que Teo se deixa mover por um destino trágico do qual tem consciência desde a primeira linha do romance.

“Teo dizia: 'somos cinco, mas um morreu', quando perguntavam quantos irmãos eles eram. Se a pessoa estranhava, ele balançava a cabeça e dizia 'eu não o conheci, era o mais velho e morreu nenê'." (BRACHER, 2007, p. 7). A passagem que abre o romance dá voz a Teo a partir da lembrança de Raul. Fica claro que chama a atenção do narrador e melhor amigo do personagem essa declaração dramática a respeito do irmão morto que ele nem chegara a conhecer.

A escolha de Raul como um dos narradores parece fundamental, pois ele é o narrador que descreve a família no passado com menos paixão, porém com mais intimidade em relação aos momentos de juventude. Raul tem uma memória extraordinária e se descreve como "plagiador profissional". 0 caráter pragmático de Raul se apresenta em sua forma narrativa, mais direta ao reproduzir falas de Teo e falas de Xavier (pai de Teo), formando uma cadeia de informações passadas de um para o outro, aparentemente de forma objetiva e precisa, expressa por meio das aspas, usando o chamado discurso direto. Mesmo convivendo com a família não tradicional, Raul continuava apegado a valores conservadores. Essa expressão narrativa objetiva é uma forma de representar literariamente a personalidade do narrador/personagem. 
Havia a violência das ideias, uma obrigação de estar aberto ao mundo, de submeter tudo à análise, à curiosidade e ao gosto. Com toda essa carga de cultura e liberdade, eu gostava de ser apenas um agregado e ter minha casa fechada e mobiliada para onde ir. (BRACHER, 2007, p. 12-13).

A oposição entre liberdade e violência, espaço aberto e espaço fechado definem Raul e Teo. Por outro lado, a segunda narradora do romance é Isabel, mãe de Teo. A avó de Benjamim é a narradora que mostra mais compreensão em relação a Teo, porque tem mais compreensão em relação à vida:

Benjamim, esta história são nossas vidas e ainda não acabou, nunca vai acabar. Criar esse espaço para a tua mãe, essa narrativa para teu pai e teu avô, como se vida não tivesse existido entre um Benjamim e outro, tivesse sido apenas um oco, lapso, vão entre um amor perdido e seu reencontro, isso é pouco. Veja, Benjamim, faz sentido, mas um sentido pobre, não somos literatura, querido. Muito amor, esperma, sangue, risos, ódios, mortes, doenças, catarro, puns, banhos, remédios, escolas, provas, violão, inglês, natação, balé, empregadas, babás, unhas cortadas [...] tempo e muito mais correu entre um e outro encontro, e isso é você também, e é bem mais complicado do que uma história de amor. (BRACHER, 2007, p. 20).

Isabel se coloca como um ser fora do papel, é a personagem mais consciente da multiplicidade de vidas que se pode viver, da trama entre o belo e o feio, da importância do caminho que se percorre. Ao dizer que eles não são literatura e que é mais que uma história de amor, ela põe em xeque os sentidos tradicionais de literatura e mostra que se vive o corpo, a razão e a emoção.

O terceiro narrador, Haroldo, é amigo dos pais de Teo, mais especificamente de Xavier. Sua análise é mais comparativa do que a dos demais narradores. Ele compara Xavier com Teo em suas aparências, loucuras e escolhas: "Nessa visita ele me mostrou um retrato do Teodoro. Era a cara dele quando fomos colegas. 0 mesmo jeito de ombro, o mesmo olhar, cor da pele, tudo igual. Tua mãe deve ter tomado um susto" (BRACHER, 2007, p. 22). Ele foi o único que conheceu a mãe dos dois "Benjamins" - o filho mais velho de Xavier e o filho único de Teo.

Esse narrador é o mais distante emocionalmente da família, sua maior preocupação é com Isabel, por quem nutriu um sentimento não correspondido. Tal distanciamento pode ser percebido por uma narrativa com maior presença de travessões nas falas, remetendo a uma tentativa de maior fidelidade no relato, além de expressar sentimentos menos afetuosos em relação a Teo: “Conheci o Teodoro, teu pai, 
ainda criança pequena e depois já maluco, carcomido pela doença e acabando com minha amiga Isabel." (BRACHER, 2007, p. 22)

A união dessas três perspectivas cria uma narrativa em que a vida de Xavier e Teo é reconstruída diante dos olhos de Benjamim - e consequentemente do leitor - em busca da interpretação da tragédia que se abateu sobre a família. A viagem é a linha que dá unidade aos discursos dos narradores. Esta, presentificada na voz de Raul por sua experiência com Teo no sertão; encenada no (re)encontro com o filho e com o neto por Isabel; e reescrita por Haroldo através da lembrança de Xavier.

\section{0 viajante}

Sair de São Paulo, para Teo, é fugir das fórmulas preconcebidas de sucesso. 0 sertão é sua obsessão. "Ele escrevia, telefonava de vez em quando, dizia que estava refazendo os caminhos de Guimarães Rosa e se aperfeiçoando em modas de viola, isso foi no início." (BRACHER, 2007, p. 17). Essa passagem, narrada por Isabel, mostra como a relação do sertão com a obra rosiana é fundamental na narrativa contemporânea, especialmente por se tratar de um drama existencial, cujas paixões levam à tragédia. Ao tematizar a tragédia existencial do viajante em Náufragos da esperança (2012), a ensaísta e professora da Universidade Federal Fluminense, Lúcia Helena, ressalta esse aspecto na literatura nacional:

\footnotetext{
Na literatura brasileira, em 1956, o percurso da vida é metaforizado como uma travessia pelo sertão, o que vale para a existência como um todo. A tal ponto, viver torna-se, na concepção de Riobaldo, protagonista de Grande Sertão: veredas, um "negócio muito perigoso", como se todos trafegassem sob a ameaça de serem tragados por um redemoinho. (HELENA, 2012, p. 23).
}

Quando viaja, Teo tem apenas 18 anos, contudo, por sua vasta cultura e pela formação libertária dada por seus pais, ele está consciente do que busca. Tanto que cita Guimarães Rosa, o que mostra ao leitor que esse não é apenas um recurso intertextual promovido pela autora Beatriz Bracher para dialogar com a literatura. É, na verdade, um diálogo da personagem Teo com os sentidos trágicos elaborados pela arte de seu tempo.

Na interpretação poético-literária da obra de Guimarães Rosa, Benedito Nunes (2013) mostra o tema da viagem, presente também em Cervantes e Joyce, como forma de dar sentido à existência: 
Existir e viajar se confundem. A existência de Riobaldo totaliza-se como viagem finda, que precisa ser relatada para que se perceba o seu sentido. Unem-se, nessa viagem, sob a forma de relato, os diferentes fios do Bem e do Mal, que compõem o emaranhado da existência. Vivendo de momento a momento, de lugar a lugar, sem a compreensão da linha temporal e sinuosa que liga todos os momentos e todos os lugares da existência, só percebemos saídas e entradas, idas e vindas. Mas a viagem redonda, a travessia das coisas - que é vivência e descoberta do mundo e de nós mesmos, nessa aprendizagem da vida, em que o próprio viver consiste -, a viagem-travessia que se transvive, na lembrança, constitui o saldo imponderável das ações, que a memória e a imaginação juntas recriam. (NUNES, 2013, p. 80).

A citação de Nunes aprofunda a relação viagem-existência. Na obra de Guimarães Rosa a viagem é a própria existência, apenas na travessia é possível dar sentido à vida humana. Nessa citação também estão presentes duas ideias fundamentais para este artigo: memória e imaginação. Em Antonio, a memória de três narradores monta o quebra-cabeça da vida de Teo. Cada um deles conhece um trecho da travessia do protagonista, trecho que eles não apenas relatam: eles o interpretam. E assim, recriam.

A viagem parece inscrita em Teo, um destino inescapável para o qual contribuem sua formação intelectual, além da história pregressa da família. A decisão de sair de São Paulo culmina quando Xavier, seu pai, conta a origem da expressão "tenho cinco filhos, mas um morreu", dita e repetida como uma espécie de charada. Ele ouve de seu pai a história da morte de seu primeiro filho, Benjamim, com sua primeira esposa, Elenir. Tal acontecimento causou um forte transtorno mental em Xavier, levando-o à internação em um sanatório. Para superar a perda, Xavier passou de um advogado tradicional, a um artista libertário, porém, sem jamais deixar de incluir esse filho entre sua prole. Desde esse momento, Teo parece se sentir parte dessa história, mas ainda não sabe o porquê: "Do jeito que ele falava, parecia que eu tinha alguma coisa a ver com esse primeiro filho, uma coisa meio maluca" (BRACHER, 2007, p. 12).

Essa sensação de fazer parte da história é um dos impulsos que levam Teo a sair de casa. A relação entre a história de Xavier e Teo se concretizará no futuro, quando Teo se casa com Elenir e tem um filho com ela, Benjamim. Ele repete a história do pai, porém aprofunda-se na loucura que o matará. Parece haver um destino trágico para o qual a personagem é levada. Não é racionalidade, apenas emoção.

Cada um dos narradores conta uma parte da vida de Teo, incluindo o que sabem sobre as viagens que ele fez. Entretanto, o que importa não é a descrição da viagem em 
si, pois temos um romance em que as ações pouco são encenadas, o importante é a análise dessas ações, as consequências emocionais delas para Teo e para as outras personagens envolvidas. Essa forma dramática de narrar é possibilitada pelo tratamento existencialista dado à narrativa.

Dentre os narradores, Raul é o que primeiro tem contato com Teo fora de São Paulo. Por ser seu amigo de juventude, tenta manter essa amizade buscando viver um pouco do que Teo vive, tentando entender sua escolha e apreciar, também, essa nova vida. Os dois são, entretanto, muito diferentes, o que faz com que Raul precise lutar para se manter ao lado do amigo. A primeira impressão que Raul tem ao rever Teo é a mudança física. Neste romance a metamorfose imagética de Teo é um espelhamento da metamorfose íntima. Torna-se, portanto, essencial o atributo da beleza, dado à personagem desde o início do romance, seguindo ao longo da narrativa um percurso de transformação e deterioração. “O teu pai estava fora de São Paulo há quase um ano e, quando nos encontramos em Minas, tive dificuldade de reconhecê-lo. Ele estava superqueimado, magro, de cabelo curto e só usava short de cadarço e sandália havaiana. Parecia um menino de lá". (BRACHER, 2007, p. 30). Teo busca se mesclar à gente da cidade mineira, ele falava e agia como os habitantes locais, o que, para Raul, causou forte impressão: "Ele estava magro e feliz. Um ensimesmamento sem marola. Foi difícil para mim acompanhar". (BRACHER, 2007, p. 31).

Com esse afastamento, mudam-se também os gostos e os interesses. Raul tenta conversar, falar sobre a faculdade que cursava, os livros que estava lendo, sua nova namorada, mas Teo não se interessava por nada. Aos poucos ele vai se despindo da cultura intelectual de sua família e se tornando mais telúrico. "Teo estava se desintoxicando das palavras e do sentimento de ser especial” (BRACHER, 2007, p. 34).

A consciência trágica se manifesta inquieta, angustiada, por contrapor-se a um mundo cujos benefícios implicam não mais se aceitar a razão e a racionalidade como produtoras de um pensamento único, unidade que o sujeito trágico, que frutifica da consciência do dilema, rejeita. (HELENA, 2012, p. 47).

Esse sujeito trágico é incorporado por Teo assim que sai da cidade e chega ao interior. Ao rejeitar o pensamento único para o qual Lucia Helena aponta na citação, uma transformação acontece também no seu corpo: 
Teo contou que no primeiro mês de sua viagem vomitou muito e teve caganeira. Depois pegou a mania de cuspir. Virou um cara sujo, cuspia em si mesmo, não tomava banho, ficou com nós de poeira no cabelo. Não conseguia imaginar Teo dessa maneira em 1977, no Vale do Jequitinhona, mas antes do que veio depois. Ele disse que então resolveu cortar o cabelo como o pessoal de lá e largar suas roupas de cidade. Ficou só com uns livros, o violão e o caderno onde escrevia e desenhava. Ele se sentia sossegado e não aguentava falar. Queria tocar a trabalhar. Não queria nem pensar muito, só deixar as coisas acontecerem. (BRACHER, 2007, p. 35).

Teo despe-se da aparência e das palavras; em um processo de rejeição começa a mudar sua aparência e, aos poucos, decide não aceitar a racionalidade, como explicita Helena (2012). A imagem grotesca de Teo sujo contrasta com a imagem inicial dele no romance, ainda em casa, bonito e limpo. Cada passagem sua pelas diferentes cidades impõe de forma violenta uma mudança interna e externa. Com o tempo, Teo consegue equilibrar-se por meio da incorporação dos hábitos sertanejos. Ele, inclusive, passa a valorizar mais o trabalho braçal do que o intelectual. Como afirma Raul, "Ele agora queria ser pelas mãos". (BRACHER, 2007, p. 37). Essa postura contraria o pensamento ocidental que valoriza o trabalho intelectual, o estudo, a construção da carreira e da família. Entretanto, Teo fora criado por uma mãe que pregava a liberdade, portanto, para ele e para sua família, essa viagem não era algo tão alarmante quanto para Raul, sempre figurado como personalidade muito diferente de Teo.

O entendimento de Raul a respeito da nova vida de Teo vai aumentando conforme ele acompanha a rotina do amigo. A cena em que Raul participa do abate de um porco sintetiza a forma como a vida e a morte, o belo e o grotesco perderam as fronteiras a partir do momento em que se iniciou a viagem existencial:

Fiquei do avesso e tonto, me segurei na cabeça do bicho para não cair. Vinha um bafo quente das entranhas vermelhas. Era vida demais naquela morte. Morto o bicho, sentei-me num banquinho encostado na parede salpicada de sangue. Fiquei lá feito besta, meu corpo mole e os olhos abertos vendo Teo esfolar o animal. Teu pai tinha prazer naquilo, era preciso nos gestos, enfiava a mãe e ia puxando órgão por órgão. (BRACHER, 2007, p. 39).

Um abismo começa a se abrir entre Raul e Teo, o primeiro impressionado pela visão da morte, o segundo, entusiasmado pela possibilidade da vida. Há uma aproximação com a natureza que é, por si mesma, trágica, pois não foge ao seu destino. A experiência com a morte/vida o tornava mais forte e consolidava esses novos traços de sua persona. "Era uma atividade alegre em que todos participavam, sabiam a sequência 
certa, teu pai feliz e concentrado comandava a festa. Arriado no banquinho, eu participei dessa alegria, era bom ver o Teo daquele jeito, um moleque bonito, cheio de força." (BRACHER, 2007, p. 39).

A beleza de Teo se manifesta diante dos olhos de Raul em uma cena grotesca, marcando, assim, a diferença entre os dois. Aos poucos, Raul começa a entender que aquela viagem ia além de férias mais extravagantes: "Quando entendi que não eram férias, mas uma procura de sentido, aquilo me irritou, achei que ele estava fazendo gênero, que esse gênero era também uma censura a mim". (BRACHER, 2007, p.67). Raul se vê como a parte de Teo que está sendo recusada, sente inveja e ciúmes dos novos amigos de Teo, sente a recusa do amigo quando ele deixa de querer conversar, recusando, também, as palavras, que seriam uma forma preestabelecida de comunicação com a qual, agora, ele não se identifica mais. Há um embate de forças entre Raul e Teo, já que o primeiro representa a intromissão da vida antiga na vida nova. 0 amigo, por sua vez, insiste em ficar com Teo e o leva em uma viagem pelo rio São Francisco.

Há uma força presente no fato de se fazer uma viagem através de um rio, principalmente quando se envolvem nela personagens urbanos como Raul e suas amigas. Eles estão buscando o exotismo da vida ribeirinha, as belezas naturais brasileiras, como numa viagem no tempo, em que voltassem aos temas do romantismo, exaltando a natureza e o povo da terra, entretanto, tudo isso é apenas fingimento poético, pois em alguns dias voltarão para suas universidades, empregos e família.

Ao aceitar participar da viagem, Teo marca o grupo com seu signo trágico. A viagem não será apenas diversão e turismo, a presença dele vai expor a precariedade existencial de todos ali, metaforizada pelo barco que os leva ao longo do rio.

No barco ele foi ficando mais exibido, de um jeito meio agressivo. Nem sei se este vapor ainda existe. Ele funcionava com lenha, de vez em quando tínhamos que parar na margem para cortarem madeira. Era bem precário, servia para as pessoas irem de uma cidade a outra ao longo do rio, não era barco de turista. No segundo andar havia cabines com camas, almoço em mesas. Nós viajamos na segunda classe, ficávamos embaixo, no convés, dormíamos no mesmo chão onde comíamos. (BRACHER, 2007, p. 69).

O próprio estar no barco era uma aventura para os paulistas, já Teo "era o cara do lugar" (BRACHER, 2007, p. 70), sabia como se comportar, fez amizade com todos e, aos poucos, foi perdendo traços da sua criação moderna e urbana, tornando-se mais parecido com os homens rudes e machistas, apropriando-se, assim, de mais uma nova 
identidade. A tensão vai ficando mais forte entre os membros do grupo, conforme Teo vai incorporando essa nova persona: "O clima pesou entre nós, a brincadeira deles exigia uma plateia e não estávamos a fim de participar" (BRACHER, 2007, p. 71). As amigas de São Paulo e Teo começam a se relacionar de forma agressiva e ela chega a agredir fisicamente uma delas. As moças, entretanto, estavam enredadas e participavam do teatro com prazer, sem imaginar que o drama que encenavam era uma tragédia.

Uma conversa de Teo com Carmem, namorada de Raul, o protagonista, elucida os motivos de seu comportamento. Ele deseja punir esses amigos que vão ao interior em busca de diversão e exotismos:

Vadiagem de férias. Mas o povo daqui fica, a igreja fica, e as casas tem donos, não existe pausa nem férias e nada é simples. Por isso é preciso que elas sintam o corpo, que o corpo seja ferido, dominado, para surgir um rosto com nome, uma coisa que seja só delas e de ninguém mais, nem que seja a dor e o sangue, para que exista alma. (BRACHER, 2007, p. 75).

Nesse momento, Raul conta a Benjamim conversas e histórias narradas a ele por outras pessoas (no caso da citação acima, Carmem). Tal mecanismo aprofunda a ideia de que as ações importam menos do que o relato reflexivo das mesmas. Carmem não narra a agressão de Teo às moças, ela narra a justificativa social e filosófica que a personagem dá a sua conduta. Para ele, corpo e alma estão intrinsecamente conectados e seu conhecimento disso lhe dá o direito de impingir o sofrimento físico, consequentemente emocional, a elas. Tal aprofundamento da tensão corpo-espírito, cidade-sertão, culmina na cena trágica em que Teo dá uma pedrada na cabeça de um homem - motorista de um caminhão que leva peregrinos. Esse homem havia abordado Teo, Teresa e Filó em um bar do povoado reivindicando participação no grupo, pois havia duas mulheres para um homem. As moças, que tentavam mostrar liberdade, aceitaram, inicialmente a brincadeira, contudo não estavam dispostas a ter um relacionamento físico com o homem: "Teresa não parava de chorar, ela dizia, ele tem um dente podre, ele tem um dente podre." (BRACHER, 2007, p. 76). A rejeição provoca fúria no homem que ataca Teo com uma faca, porém, mesmo ferido, Teo consegue alcançar uma pedra e o acerta na cabeça, deixando o homem desacordado no chão. Nunca se soube se o homem havia morrido ou não, contudo, esse desenlace trágico da viagem causa em Teo nova transformação: “Teo acordou com o barulho e não conseguiu mais dormir. Acho que ele morreu, ele disse, acho que matei o filho da puta. Vão ter que arrumar outro motorista. 
Os crentes, os fiéis, os pagadores de promessas vão ter que se virar. Eu também". (BRACHER, 2007, p. 78).

O martírio físico que Teo julga necessário para a transformação da alma o leva a uma nova transmutação. Depois de se recuperar da facada e de terminar a viagem ao São Francisco, ele vai viver no Cipó, em Minas Gerais. A partir daí perde contato com Raul, que só voltará a encontrá-lo no retorno de Teo à cidade, já doente. A narradora que nos guia por esse trecho do percurso é Isabel, sua mãe. Ela vai em busca de notícias do filho e acaba encontrando-o no Cipó, vivendo como um vaqueiro, já com o filho Benjamim. Nessa nova realidade, Teo tem outro nome: Tito. Suas maneiras são outras, Isabel já não o reconhece:

Fatos: Teodoro chegou suado e cumprimentou a todos e a mim com parcimônia educada e singela. Trouxe você junto e mandou que me pedisse a bênção, coisa que você fez com naturalidade exasperante. Nunca houve disso na nossa família. Ele não se sentou, segurava o chapéu com as duas mãos na frente do corpo, um perfeito colono da minha infância, afável e humilde. (BRACHER, 2007, p. 91).

Isabel não aceita a nova persona do filho. Diferentemente de Raul, que estranha seu comportamento, para Isabel o que mais choca está no nível da linguagem. 0 fato de não compor nem desenhar mais, a maneira como a trata: "Penso no Benjamim, nas galinhas e nos porcos. Penso na vida, senhora minha mãe". (BRACHER, 2007, p. 92). Isabel fica extremamente ofendida com o tratamento de senhora, nunca existente em sua família. Além disso, sua família havia sido educada no meio artístico e acadêmico e essa arrogância intelectual provoca extremo mal-estar ao saber que, agora, vida para ele, dava-se no plano da natureza, era nisso que pensava.

Para chegar a esse ponto da vida, Teo precisou perder a mulher, Leninha, que era a mesma mulher com quem seu pai se casara na juventude, ter um filho com ela e dar o mesmo nome do filho que ela tivera com seu pai. Precisou perder o pai. Sofrer dores físicas e emocionais. Viver na natureza para desintoxicar-se da cultura.

Seu percurso trágico começa a findar-se quando é levado de volta a São Paulo por causa de uma doença. Para Isabel não importa de fato que nome essa doença teria. $\mathrm{Na}$ tentativa entender a loucura final do filho: 
dos parentes. Aliás, os dois fatores são um só. São os parentes que não suportam a loucura. Ou talvez seja o louco que não suporte sua condição ao lado de parentes. Ou ainda, toda família precisa de alguém para ocupar o papel de louco. Depois da morte de Xavier, coube a Teo a obrigação de desempenhálo, e ele não soube fazer com o mesmo savoir vivre do pai, que sempre tirou proveito de seu personagem na profissão, na família, nas camas em que esteve. (BRACHER, 2007, p. 136).

Isabel analisa Teo como espelhamento de Xavier. Assim, como todo o espelho, a imagem refletida não é idêntica, pois é filtrada pelos olhos de quem vê, além de ser alterada pelo formato e defeitos do espelho. 0 destino trágico de Teo já estava sendo preparado por Xavier, pois a história de Teo é uma história de família e toda história de família pressupõe uma travessia no tempo.

A loucura de Teo é agressiva com os que estão ao seu redor, ela degrada o ambiente ao seu redor, assim como seu corpo.

\begin{abstract}
Abri a porta e vi com um olhar de microscópio cada pedacinho de caos. Cascas de laranja, bitucas de cigarro, pedaços de metal e de plásticos, restos de aparelhos eletrônicos e de móveis, cacos de vidro [...]. Além do quarto-lixo, uma crosta de sujeira e cola crescia em seu próprio corpo. Na cozinha fazia cola de farinha com a qual unia disparidades, havia cola de dias em seus braços, rosto e cabelo, além da sujeira da rua, do suor e da própria saliva que ele cuspia em si mesmo em um movimento nervoso de que não se dava mais conta. Sim, eu sei que você acompanhou tudo isso, mas eu preciso falar, preciso lembrar, preciso saber. (BRACHER, 2007, p. 138-139).
\end{abstract}

A simbiose corpo-espírito está chegando à sua culminância trágica. Tudo se deteriora em Teo. Sua imagem se parece com a descrição feita por Raul da primeira viagem, ou seja, essa retomada é a marca da última viagem de Teo, de volta a São Paulo, definitivamente alienado da realidade sociocultural. No período final da citação destacase a consciência de Isabel de que falar é saber: a narrativa é uma forma de conhecimento. Isabel, aliás, é a narradora que mais realiza interpretação à luz da literatura. Ao falar sobre a aparência do filho já no fim da vida ela afirma, referindo-se a Haroldo, amigo da família e terceiro narrador do romance:

Ele não foi capaz de enxergar Teodoro, a beleza de um jovem alucinado, beleza não da alucinação, esta é bonita apenas nos romances, ele não era capaz de ver a beleza do jovem Teodoro, seus olhos cheios de brilho, os cabelos muito pretos e ondulados, o corpo magro e o seu modo de andar e mexer as mãos como um gato magro e vadio, a boca já meio roxa, fina e bem desenhada. Haroldo só conseguia ver a loucura e como isso me destruía. (BRACHER, 2007, p. 140). 
A narradora mais intelectualizada enxerga beleza no trágico e respeita a solidão da loucura e da doença que logo iria matá-lo. Pode-se atribuir essa compreensão ao fato de ela mesma, Isabel, estar com câncer terminal quando conversa com Benjamim. Por ser um romance de recuperação de memórias, no momento em que essas memórias chegam à boca dos personagens/narradores, elas passam pelo filtro do tempo, das emoções, das circunstâncias atuais. Isabel analisa o fim trágico do filho pelo olhar de quem está para morrer.

A figura agonizante de Teo causa muito sofrimento em Isabel, fato que torna Haroldo menos sensível a seu sofrimento. 0 terceiro narrador narra sempre usando um espelho em que Teo reflete Xavier, personagem que conhece muito bem. Haroldo é representante da ideologia conservadora, entende que vencer em São Paulo é vencer na vida: "Por outro lado, só na cidade de São Paulo se é alguma coisa, disso eu estou seguro, ao menos se estamos falando de Brasil [...]. Por mais que se trabalhe no Rio de Janeiro, Belo Horizonte ou Porto Alegre, nada vingará se não passar por São Paulo" (BRACHER, 2007, p. 107-108).

Enquanto Raul se esforçava para compreender o amigo, admirando-o, tentando fazer parte de sua vida, Haroldo despreza a forma como Teo e Xavier produziram conhecimento de vida:

\footnotetext{
Ao teu pai não, esse seria seu legítimo herdeiro. Ele via Teodoro repetir o que ele mesmo fizera quando fomos juntos para a Europa. Como se ele tivesse feito grande coisa por lá. Eu fiz meu mestrado em uma Paris pós-guerra, machucada, esquizofrênica. Ele viveu a cidade de noite, os bares, a descoberta de um outro teatro. De alguma forma foi seu mestrado também. (BRACHER, 2007, p. 115).
}

Para Haroldo, o aprendizado de Xavier, na noite de Paris, embora tenha sido uma espécie de mestrado, não foi "grande coisa". Essa postura se mostra ao longo dos trechos narrados por ele, por meio de expressões características da cultura conservadora, machista e elitista. As diferenças e semelhanças entre personagens/narradores e Teodoro/Xavier formam um todo dissonante que permite chegar ao cerne da vida de Teo e de sua família, que produziram uma história cheia de lacunas, dramas e obsessões. 


\section{Consideração finais}

0 romance Antonio, de Beatriz Bracher, merece ser lido de forma mais profunda, pois é uma obra em que muitos sentidos e emoções de mesclam. Caminhos tripartidos com muitas possibilidades de rotas e interpretações. Esta foi uma breve leitura que partiu do tema da viagem, levando em consideração que o ponto central do romance é a tragédia existencial de Teo, expressa em seu corpo por meio da gradual degradação física e psicológica do personagem.

A contemporaneidade do romance dialoga com valores da antiguidade como a beleza noturna de Dioniso, tão desgarrada da razão. Mostra-se como reflexão sobre a importância da liberdade; inclusive para ser louco; inclusive para morrer. Teo é a representação da coragem de seguir seu destino trágico, entendido como única possibilidade de viver. Tal percurso é também um fio condutor para que os demais personagens, sejam os narradores, o ouvinte ou aquele que ainda não nasceu, entendamse como existências marcadas pelas paixões.

\section{Referências}

BRACHER, Beatriz. Antonio. São Paulo: Ed. 34, 2007.

ECO, Umberto. História da beleza. Tradução Eliana Aguiar. Rio de Janeiro: Record, 2004.

HELENA, Lucia. Náufragos da esperança. Rio de Janeiro: Oficina Raquel, 2012.

RESENDE, Beatriz. Contemporâneos: expressões da literatura brasileira no século XXI. Rio de Janeiro: Casa da Palavras: Biblioteca Nacional, 2008.

NUNES, Benedito. A Rosa o que é de Rosa: literatura e filosofia em Guimarães Rosa. Organização Vitor Sales Pinheiro. Rio de Janeiro: DIFEL, 2013. 